716

\section{MINI-DOSE OF GLUCAGON: GREAT EFFICACY AVOIDING ADMISSION OF INSULIN-DEPENDENT-DIABETIC CHILDREN WITH DECREASING NORMOGLYCEMIE OR HYPOGLYCEMIE DUE TO VOMITING OR GASTROENTERITIS}

T.M. Jimenez Busselo, J. Aragó Domingo, E.M. Marra

Pediatric Emergency Department, Hospital Universitario La Fe, Valencia, Spain

Study Objective: To assess the efficacy and safety of subcutaneous Glucagon-minidose (GCGmd) administered in the Emergency Department (ED) to treat insulin-dependent diabetic children with decreasing normo-glycemie or asymptomatic hypoglycemie resulting from acute gastroenteritis or persistent vomiting.

Methods: a retrospective study of two cohorts of insulin-dependent patients presenting to our ED between 2004 and 2010 under the above circumstances, being separated into two groups based on whether they received GCG-md (Group-A) or not (Group-B). Outcomes were compared based upon their admission rates, average length of hospital stays (LHS) and rate of i.v. fluid therapy (ivFT). Guidelines for GCG-md administration were initiated in our ED in June 2008 but, in 2009, we also began the use of sublingual Ondansetrón (sIOS) for persistent vomiting; then, its influence on our results was assessed.

Results: 7 patients were included into group $A$ and 21 into group $B$. The average glycemic increase after GCG-md was $47 \mathrm{mg} / \mathrm{dl}$ (18-66). The relative risk $(R R)$ of admission in group $A$ compared to group $\mathrm{B}$, was $1 / 6=0.166(95 \% \mathrm{Cl}: 0.05-0.49)$ with resulting NNT $=1.4(95 \% \mathrm{Cl}: 1.05-2.38)=10$ cases treated avoid 7 admissions. The average LHS was significantly shorter $(p<0,005)$ for group A vs. group B. The RR of ivFT in group $A$ was $0.187=1 / 5.3(95 \% \mathrm{Cl}: 0.123$ $0.28), \mathrm{NNT}=1.61(95 \% \mathrm{Cl}: 1.07-3.3)=8$ cases treated avoid 5 ivFT.

Conclusions: GCG-md is very effective in managing the described situation: it rescues patients from risk of hypoglycemie, avoids ivFT and hospitalizations and shortens the LHS. It's suitable to instruct families for its use at home. The use of sIOS didn't influence our results

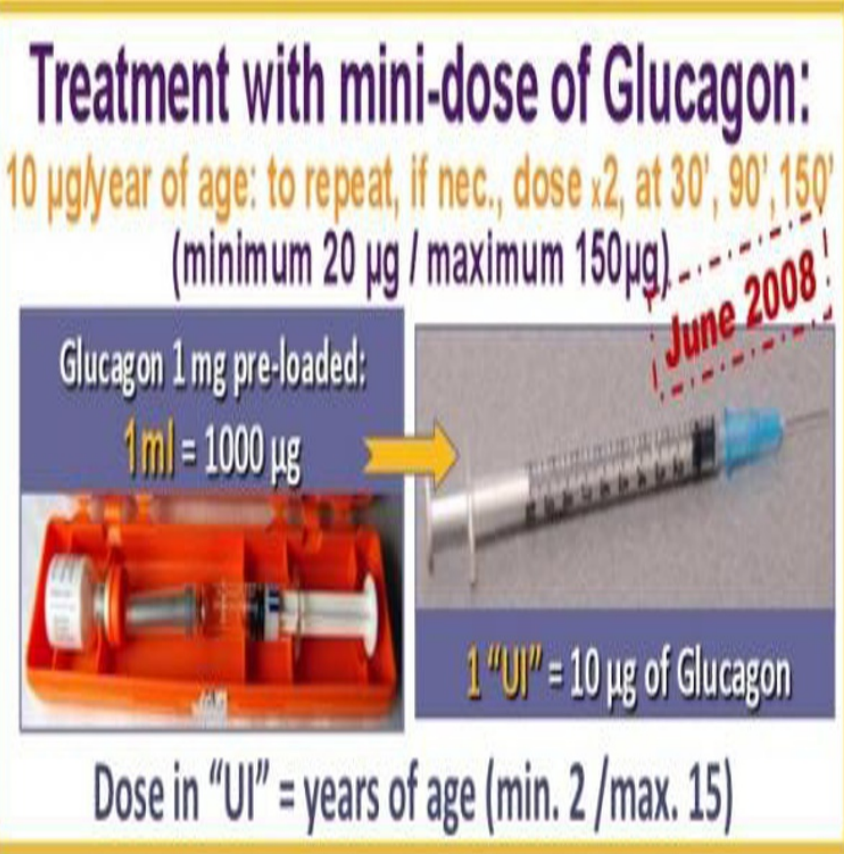

[Glucagon_md_guideline]

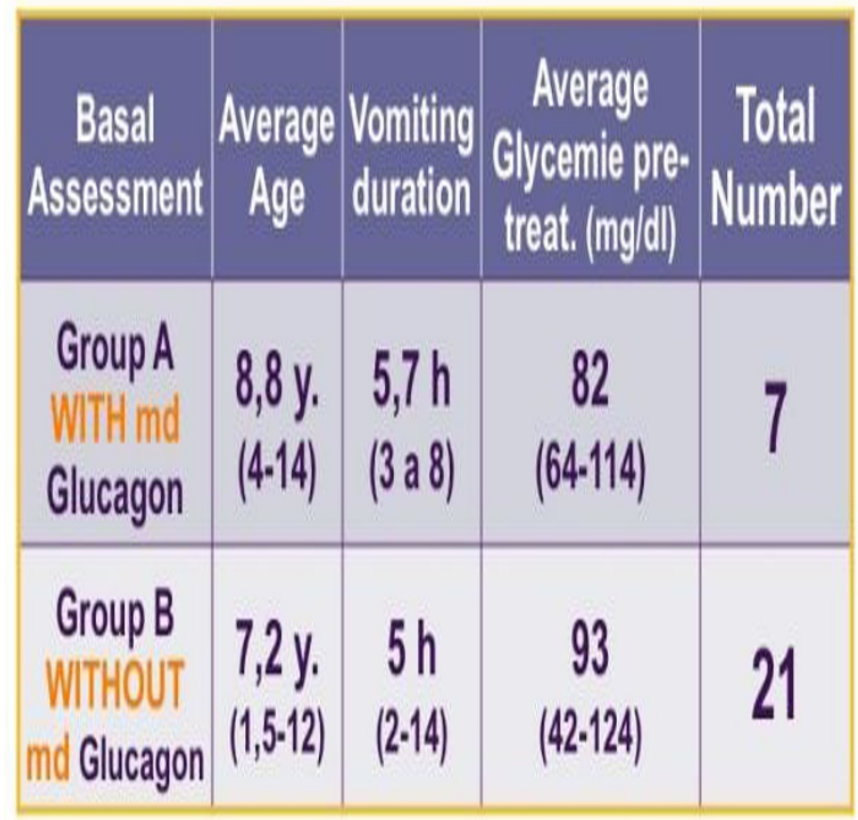

[Glucagon_md_basal_assessment] 


\begin{tabular}{|c|c|c|c|c|c|}
\hline \multirow{2}{*}{ Outcomes } & \multirow{2}{*}{$\begin{array}{l}\text { Length of } \\
\text { Hosp. } \\
\text { Stay }\end{array}$} & \multicolumn{2}{|c|}{ H. Admission } & \multicolumn{2}{|c|}{ iv Fluid-Therap. } \\
\hline & & YES & NO & YES & NO \\
\hline $\begin{array}{l}\text { Group A } \\
\text { WITH mdG }\end{array}$ & $\begin{array}{l}5,6 h \\
(2-26)\end{array}$ & $\begin{array}{c}1 \\
(14,3 \%)\end{array}$ & 6 & $\begin{array}{c}1 \\
(14,2 \%)\end{array}$ & 6 \\
\hline $\begin{array}{l}\text { GroOup B } \\
\text { WITHOUT } \\
\text { mdG }\end{array}$ & $\begin{array}{l}21,6 \mathrm{~h} \\
(2,5-60)\end{array}$ & $\begin{array}{c}16 \\
(85,7 \%)\end{array}$ & 5 & $\begin{array}{c}18 \\
(76,2 \%)\end{array}$ & 3 \\
\hline \multicolumn{2}{|c|}{$\begin{array}{l}\text { Glycemic } \uparrow \text { post-mdG: } \\
47 \mathrm{mg} / \mathrm{dl}(18.66)\end{array}$} & \multicolumn{2}{|c|}{$\begin{array}{l}\text { Relative Risk: } \\
0,166=1 / 6 \\
(\mathrm{Cl} 95: 0,05-0,49)\end{array}$} & \multicolumn{2}{|c|}{$\begin{array}{l}\text { Relative Risk: } \\
0,19=1 / 5,3 \\
\text { (CI 95: 0,123-0,28) }\end{array}$} \\
\hline
\end{tabular}

[Glucagon_md_outcomes]

717

BONE STATUS IN CHILDREN AND ADOLESCENTS WITH TYPE 1 DIABETES MELLITUS: CURRENT CONCEPT

N.H. Abu Faddan', E. Hamed², D. Sayed ${ }^{3}$, H.A. Abd Elhafeez ${ }^{3}$

${ }^{1}$ Pediatrics, ${ }^{2}$ Physiology, ${ }^{3}$ Clinical Pathology, Assiut University, Assiut, Egypt

Background: There is recent considerable evidence supporting vitamin $D$ deficiency role in pathogenesis of type 1 diabetes mellitus (T1DM) resulting in alteration in bone metabolism and structure and higher risk of related complications later in life.

Aim: The present study aimed to evaluate alteration of bone status and possible association between 25-hydroxy D3 [25 (OH) D3], parathormone [PTH], insulin growth factor -1 [IGF-1] serum profiles, glycemic control and disease duration with bone mineral density (BMD) in a children and adolescence with uncomplicated T1DM.

\section{Methods:}

Thirty six children and adolescents (mean +/- SD age, $10.38+/-3.17$ years) with T1DM were matched with $15(8.47+/-4.17$ years $)$ healthy controls. Serum levels of $25(\mathrm{OH})$ D3, PTH, IGF-1 were measured by ELISA while, glycosylated hemoglobin $(\mathrm{HbA} 1 \mathrm{c})$, calcium $(\mathrm{Ca})$, inorganic phosphorus $\left(\mathrm{PO}_{4}\right)$ by spectrophotometer. Bone quality was determined by dual energy X-ray absorptiometry (DEXA).

Results: Children and adolescents with T1DM showed increased serum levels of $\mathrm{PO}_{4}$ and $\mathrm{PTH}$ and decreased calcium, IGF-1, $25(\mathrm{OH})$ D3 About $52.8 \%$ of our patients had insufficient $25(\mathrm{OH}) \mathrm{D} 3$ levels. Abnormal bone status was found in arm, ribs, T-spine, L-spine, leg, total body while head showed normal bone currency. Longer diabetic duration and poor metabolic control had a negative; meanwhile PTH, IGF-1 had a positive impact on bone mass.

Conclusions: Given that individuals with T1DM possess multiple risk factors for skeletal fragility, ensuring vitamin D sufficiency throughout childhood and adolescence in this population seems especially warranted.

Keywords: Bone mineral density; Type 1 diabetes mellitus

\section{8}

\section{CHANGES IN THE BCAA METABOLISM IN NORMAL AND DIABETIC PREGNANCIES. IMPLICATION FOR MATERNAL-FETAL INTERMEDIARY METABOLISM}

E. Diamanti ${ }^{1}$, E. Agakidou ${ }^{1}$, A. Savvidis ${ }^{2}$, I. Papoulidis ${ }^{3}$, I. Stergioudas ${ }^{2}$, I. Tzafetas ${ }^{2}$, V. Drosou ${ }^{1}$, A. Evageliou ${ }^{4}$

${ }^{1} 1$ st Dept of Neonatology, ${ }^{2} 2 n d$ Dept of Obstetrics and Gynecology, Aristotle University of Thessaloniki, ${ }^{3}$ Eurogenetica Lab, ${ }^{4} 4$ th Dept Of

Pediatrics, Aristotle University of Thessaloniki, Thessaloniki, Greece

Although previous studies have underlined the importance of branched-chain aminoacids (BCAA) in normal pregnancy, little is known with regard to the metabolism of BCAA in diabetic pregnancy.

Objective: To delineate the role of the BCAA metabolism in normal and diabetic pregnancies and their significance in fetus/neonate metabolism.

Methods: Concentrations of leucine and valine were measured in 43 pregnant women (17 diabetic and 26 non-diabetic) before delivery and in their neonates at birth. The reference group consisted of 6 non-pregnant women. BCAA evaluation was performed in dry blood spot by using Tandem MS/ MS technology. 